\title{
Erratum to: Microsatellite instability in colorectal cancer: from molecular oncogenic mechanisms to clinical implications
}

\author{
Aziz Zaanan • Katy Meunier • Fatiha Sangar • \\ Jean-François Fléjou • Françoise Praz
}

Published online: 31 May 2011

(C) International Society for Cellular Oncology 2011

\section{Erratum to: Cell Oncol.}

$$
\text { DOI 10.1007/s13402-011-0024-x }
$$

In the above mentioned review two errors in the legend of Fig. 1 has escaped the author's attention during proofreading. The correct legend of Fig. 1 should read:

The online version of the original article can be found at http://dx.doi. org/10.1007/s13402-011-0024-x.

A. Zaanan $\cdot$ K. Meunier $\cdot$ F. Sangar $\cdot$ J.-F. Fléjou $\cdot$ F. Praz INSERM, UMR_S 938, Centre de Recherche Saint-Antoine, 75012 Paris, France

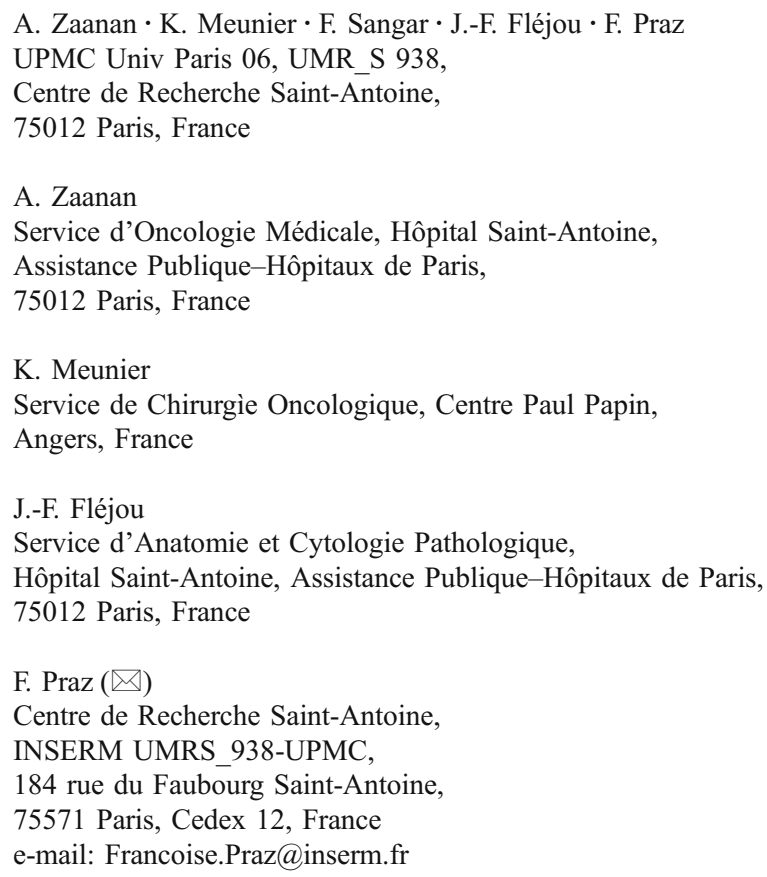



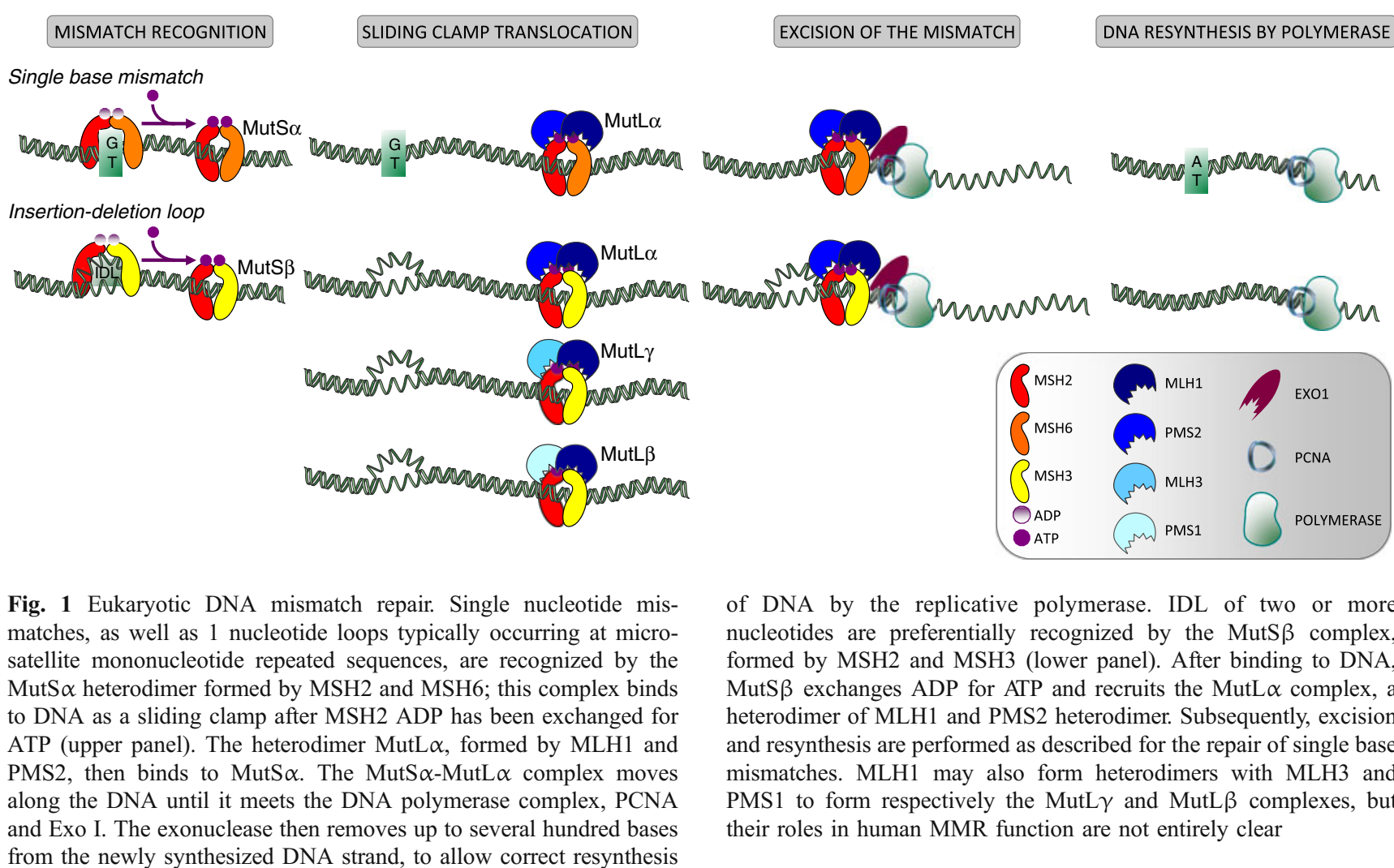

monn
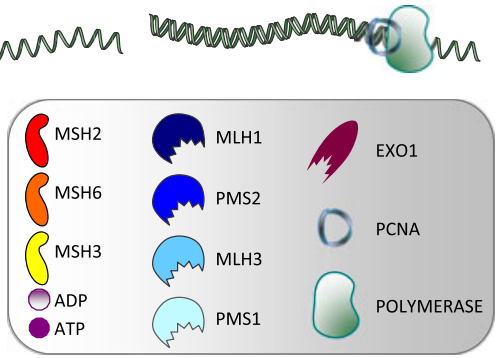

Fig. 1 Eukaryotic DNA mismatch repair. Single nucleotide mis-

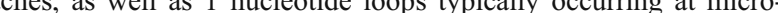
MutS $\alpha$ heterodimer formed by MSH2 and MSH6; this complex binds to DNA as a sliding clamp after MSH2 ADP has been exchanged for ATP (upper panel). The heterodimer MutL $\alpha$, formed by MLH1 and and Exo I. The exonuclease then removes up to several hundred bases from the newly synthesized DNA strand, to allow correct resynthesis of DNA by the replicative polymerase. IDL of two or more nucleotides are preferentially recognized by the MutS $\beta$ complex, formed by MSH2 and MSH3 (lower panel). After binding to DNA, MutS $\beta$ exchanges ADP for ATP and recruits the MutL $\alpha$ complex, a heterodimer of MLH1 and PMS2 heterodimer. Subsequently, excision and resynthesis are performed as described for the repair of single base mismatches. MLH1 may also form heterodimers with MLH3 and PMS1 to form respectively the MutL $\gamma$ and MutL $\beta$ complexes, but their roles in human MMR function are not entirely clear 